\title{
Essay \\ The Construction of an Undergraduate Creativity Seminar 33 Years in the Making
}

\author{
Beth A. Hennessey
}

Citation: Hennessey, B.A. The Construction of an Undergraduate Creativity Seminar 33 Years in the Making. Educ. Sci. 2022, 12, 149. https://doi.org/10.3390/ educsci12030149

Academic Editors: Sareh Karami, Gary McPherson and

Robert J. Sternberg

Received: 8 January 2022

Accepted: 18 February 2022

Published: 22 February 2022

Publisher's Note: MDPI stays neutral with regard to jurisdictional claims in published maps and institutional affiliations.

Copyright: (C) 2022 by the author. Licensee MDPI, Basel, Switzerland. This article is an open access article distributed under the terms and conditions of the Creative Commons Attribution (CC BY) license (https:// creativecommons.org/licenses/by/ $4.0 /)$.
Department of Psychology Wellesley College, Wellesley, MA 02481, USA; bhenness@wellesley.edu

\begin{abstract}
For 33 years, I offered an undergraduate, upper-level seminar on the Psychology of Creativity. A review of nearly three dozen versions of seminar syllabi, readings, assignments and student work reveals a chronicling of the evolution of the study of creativity as well as the evolution of classroom teaching, student sensibilities, and my own changing views.
\end{abstract}

Keywords: creativity; positive creativity; negative creativity; chronological evaluation of syllabi

The study of creativity has had a long, and sometimes circuitous, history. Detailed theory building coupled with literally thousands of empirical studies have taught us much about this ephemeral and essential construct. Creativity is what drives civilizations forward [1]. Without it, humankind would still be at square one.

One obvious way to explore our growing understanding of creativity would be to study the changes made to theoretical models and experimental investigations over time. Towards this end, an extensive search of the literature would serve us well. Additionally, in fact, there have been a number of comprehensive reviews carried out-including my own Annual Review paper co-authored with Teresa Amabile (Hennessey and Amabile, 2010). In this paper, however, I have chosen a different path. Having recently retired from my position of Professor of Psychology at Wellesley College, I was faced with the gargantuan task of cleaning out my office of over 30 years. This process, painful as it was, offered a rare opportunity to step back and examine the evolution of my seminar on the Psychology of Creativity. In the pages to follow, a review of seminar syllabi, readings, assignments, class discussions, and student work is carried out. Embedded in these course materials is a chronicling of the recent history of the study of creativity coupled with a window into experts' changing views about the phenomenon of creativity itself, views about what is most essential in the creativity literature, and even my own views on what it means to be an effective teacher. An analysis of student writing and projects proves equally revealing. In many important and sometimes surprising ways, each decade brought with it significant changes in the interests of students enrolled in the course, their awareness of and appreciation of creativity, their expectations for the semester and their preferred modes of learning and exploration.

The earliest syllabus to be reviewed, dated 1985, got me thinking about how I initially came to decide what would be included in and what would be omitted from my course content. Because this was my first time teaching this seminar, I remember fairly distinctly my decision-making process; and in retrospect, it had not seemed all that daunting. Of course, the creativity literature was much less extensive back then, and my path seemed fairly straightforward. My major worry, in fact, was not my syllabus but the very real prospect that no one would sign up for my course in the first place, or that I would not be taken seriously. In my first few years of teaching, students could not believe that the College was even allowing me to teach a seminar on creativity. Many enrolled in the course because they saw themselves as creative and wanted to further develop that side of them. Some enrolled because they saw themselves as woefully uncreative and wondered if I 
might help them with that. Additionally, almost all of my students viewed creativity as being primarily confined to the realm of the arts.

Fortunately, my own view was far broader. I took for granted that my students needed to be exposed to a variety of the classic papers and philosophical questions that had formed the foundation of this field, and I firmly believed (and still do) that only with such an historical underpinning could they go on to appreciate the more current, contemporary questions being pursued. Towards this end, I assigned readings authored by greats such as J.P. Guilford, who gave the Presidential Address to the APA in 1950 [2], and Jackson and Messick (1965) [3], who explored conceptual problems in creativity assessment and asked whether it was the person, the process, or the response of the audience/consumer that should be emphasized. The majority of the older readings I chose had been conveniently packaged in the still-in-print 1975 volume, The Creativity Question [4]. For many years, I required my students to purchase this book, which introduced them to the writings of Sigmund Freud, Graham Wallas, Arthur Koestler, Abraham Maslow, Donald MacKinnon, E. Paul Torrance, Sarnoff Mednick, Carl Rogers, Ravenna Helson, B.F. Skinner, and the like. While instructors could worry that these papers written in the 1940s, 1950s, and 1960s might not capture the imagination of their students, in my experience, nothing could be further from the truth. Year after year, I witnessed true indignation among class members as they wrestled with Skinner's assertion that there is no such thing as creativity, but they also showed true appreciation for writings such as Helson's essay on the many barriers placed before women attempting to develop and share their own talents and innovative ideas.

As it turned out, although most all of my seminar students were juniors and seniors majoring in Psychology, their exposure to the history of Psychology had been extremely limited. These readings did much to ground not only their understanding of the building blocks of the study of creativity, but also their appreciation for the field of Psychology as a whole. The beauty of these early writings was not lost on them. In fact, one of my all-time favorite student-written reading responses centered on the 1965 Jackson and Messick classic (and some would say rather dry) theoretical paper. This student, who would go on to write a senior honors thesis under my direction, wrote:

This article is so beautiful! Parts of it made my heart swell. I thought a lot of the descriptions of creativity were just like descriptions of falling in love! I cry. I kept quoting parts of the article to my two study buddies. For example, I loved the quote, "A condensed product is an object worthy of pondering; it should be examined slowly, carefully, and repeatedly". Oh my goodness. How are we all not puddles on the ground after reading this article? Or, " ... the viewer may sometimes feel as if his expectations have been fulfilled, whereas what has really happened is that the product has made him aware of what his expectations should have been". That is seriously a pick-up line in the works. I can't get over how beautiful this article is, especially the closing sentence: "The day on which we are certain about how to construct a theory of creativity will also be the day on which we are certain about how to construct a poem". Please tell me I'm not the only one gushing over this. I think it's especially great because the article discusses the poetics of creativity-and the authors are poets.

While the ideas in this paper may have made this young and enthusiastic seminar member cry, I remember being completely overjoyed by the idea that a student could be this deeply engaged with the material. Over the years, a variety of excellent readings chronicling the history of the field appeared in the literature, and some of them, too, were added to the syllabus. Among these additional readings was Runco and Albert's 2010 chapter in the Cambridge Handbook of Creativity [5].

But historical papers were not the only focus. Over time, I assigned a variety of readings from this handbook-readings focused on everything from computer models of creativity, to prodigies, to Csikszentmihalyi's systems perspective, as well as a number of empirical journal articles. Right from the start of this course, I deemed it essential to familiarize students with the cutting-edge issues underpinning the study of creativity; 
and I, like many of my contemporaries, opted to concentrate on person, process, product, and press/place [6]. Our examination of "process" took many forms and culminated in the viewing of two amazing films: The Mystery of Picasso [7], a simply amazing French documentary showing Picasso in the act of creating paintings for the camera and Pollock [8], the extremely well-acted story of Jackson Pollock who revolutionized the art world with his most unusual (and often criticized) techniques.

As part of our exploration of "person", I assigned biographies, autobiographies and fictional accounts of creative persons. Early on, students read Lust for Life [9]. Later, I added Creators on Creating: Awakening and Cultivating the Imaginative Mind [10]. Eventually, I settled on two fictional accounts, My Name Is Asher Lev [11] tells the story of a young boy with an amazing talent for drawing living in a Hasidic community in 1940's Brooklyn. Similarly, Body and Soul [12] chronicles the development of a musical prodigy coming of age in Manhattan in the 1950s. While, on their own, both of these novels do an amazing job of capturing the creative process, the juxtaposition of the two characters' circumstances and cultural backgrounds make for a rich discussion of environmental effects.

When our focus turned toward products, I explored with my students the question of how to measure creativity (an area of research in which my colleagues and I were actively engaged). Not only did my students read about measurement, they also actively took part in the assessment process-completing a variety of creativity tests and employing the Consensual Assessment Technique (CAT) [13] to rate the creativity and technical goodness of their own and others' products. The interface between creativity and motivation and the question of how best to set up classrooms so that they would be optimally conducive to the development of student creativity also became a focus. This is my primary area of expertise, and early on, I did everything I could NOT to assign too many papers authored by myself, NOT to talk too much about my own research. I was afraid of appearing too self-centered and loathed the idea of "tooting my own horn". But, over time, I came to realize that my sharing of the details surrounding my own work demonstrated to students just how passionate one can be about research. The details I provided opened students' eyes to the intricacies of conducting research, analyzing data, and publishing. Talking about my own work allowed me to model for students the evolution of an empirical study, a model, and a theory. Research, for many of my students, came alive. They were fascinated by how I had come up with questions to investigate. They got a taste of just how difficult it is to construct an empirical paper and were surprised when I explained that my first publication ever [14], written while still in graduate school, was the only paper I have ever published without revisions.

They laughed as I described the many challenges that come with trying to conduct research in the field. As if gaining access to children and classrooms was not difficult enough, finding space can be nearly impossible (I once had to meet with young study participants in a janitor's closet). Additionally, twice during my research career, entire studies had to be scrapped right before they were to reach completion because well-meaning but confused teachers revealed to students and/or their parents study hypotheses or necessary deceptions. Teachers, like anyone unschooled in the intricacies of empirical investigation and random assignment to condition, had an extremely difficult time wrapping their heads around the fact that students and parents needed to be blind to condition. Signing a study permission slip or consent form does NOT entitle participants to full disclosure until AFTER all data have been collected. As I told my students, it was my intent to make sure that each of them left my course with a firm grasp of the scientific method and empirical research process.

Over time, I even became comfortable sharing accounts of some painfully difficult situations such as the time when there appeared a lead article in American Psychologist [15] calling into question the work of me and my colleagues. None of us had been informed that this paper was coming, nor had we been asked to serve as reviewers. Additionally, it was only after a series of heated conversations that we were "allowed" to submit only a short reply [16]. 
As explained earlier, in the first years of this course, the majority of my students enrolled with the overt goal of improving upon or finding the germs of their own creativity, and many course assignments were designed to facilitate those goals. Students were very much focused on their own, inner creative journeys, and I tried to accommodate their interests. As a class, seminar members read and completed exercises from Drawing on the Right Side of the Brain [17] (1989) and Playful Perception [18] (1984). Students also took turns presenting short creativity building exercises to the group. They kept weekly creativity journals chronicling their own creative endeavors and progress and completed final projects centered around a creativity challenge of their own choosing. These final projects truly ran the gamut, from the perfecting of the baking of a wedding cake (in anticipation of a sister's upcoming nuptials) to a semester-long effort to perfect the art of haiku writing, to a competitive swimmer's attempt to learn from the creativity literature how she might infuse new excitement and motivation into her practices.

A few years into my time at Wellesley, I had the opportunity to dip my toes into the creativity consulting waters. Students were very much interested in my experiences working with corporations and educational groups. The media was inundated with stories of young, super successful entrepreneurs and product developers, and seminar members were anxious to explore this phenomenon. Slowly but surely, like the contemporary creativity literature itself, our syllabus came to focus more and more on group creativity and innovation. I vowed that each semester, I would try to arrange the visit of at least one well-known creativity expert in the area of innovation and business; and one year, the class had the chance to meet with an Interaction Designer at IDEO, an early leader in the area of human-centered design that was particularly "hot" at the time.

Seminar members loved this focus on group work and creativity in the business world. One contributing factor to this shift in interest may have been the fact that, over time, the course came to attract many students who were not Psychology majors. Public Health enthusiasts, Economics and Engineering majors, as well as students from a variety of other disciplines came to understand that a grounding in the creativity literature would not only be interesting but also might benefit them greatly in their eventual careers. More and more, students began the semester having already explored design thinking and entrepreneurship on their own; and, over time, their sharing of and excitement about what they found caused the syllabus and class projects and discussions to morph. No longer were students surprised that the College would allow a seminar on creativity to be taught. Instead, they complained that there were not more similar creativity courses across the curriculum. (Additionally, in fact, at the time of my retirement, a few related courses, including one on the development of consumer-oriented technologies that can benefit underserved populations worldwide, had been added to the curriculum.).

By the year 2000, the seminar could not help but undergo significant change. This was the result of two major factors. First, the creativity literature had virtually exploded. In 1985, when this course was first offered, the Journal of Creative Behavior was the only Englishlanguage academic journal devoted to the study of creativity. Some 15 years later, my students and I had access to the Creativity Research Journal (1988) and the International Journal of Creativity and Problem Solving (1990) as well as a variety of scholarly journals exploring creativity from a developmental psychology, social psychology, education or business, perspective. This wealth of information would soon increase even more. In 2006, Thinking Skills and Creativity and the Psychology of Creativity, Aesthetics and the Arts arrived on the scene. Additionally, not too much later, the Journal of Gifted Education and Creativity (2014) and Journal of Creativity (2019) came into being. These new sources of information coupled with hundreds of single-authored or edited books focused on creativity and innovation, not to mention a number of excellent journals based in places around the world from Asia to Eastern Europe to Australia, now made the structuring of an undergraduate seminar on creativity next to impossible!

Adding to this deluge of research and theorizing was the fact that as the Internet became more and more available to students, journal articles, and sometimes even entire 
chapters from e-books, could be easily accessed. Entire college courses, including this creativity seminar, gradually became computer based. Wellesley College initially adopted FirstClass, a course management system, in 1999. In 2012, FirstClass was replaced by Sakai. Aided by these online tools, my teaching gradually transformed. As would be expected, syllabi and assignments, and even weekly readings, became available online. But the use of these platforms rose far beyond the simple electronic cataloging of the seminar. Over time, online discussions of weekly readings were incorporated into the course framework. Oftentimes, these lists of readings were divided into required and optional categories. Did students actually read the optional references?- perhaps not. But they did find the suggestions especially helpful towards the end of the semester when researching for a final paper. Every week, seminar members were invited to comment on the readings, post questions, respond to one another's posts and share relevant journal articles or popular press pieces they had found. In addition, PowerPoint slides of my in-class efforts to share information with students and frame their appreciation for the material they were digesting were also posted. In fact, as time went on, I became more and more likely to "flip" the classroom-requiring students to view my narrated PowerPoint presentations before coming to class, thereby freeing up valuable in-person time together for conversation, clarification, and discussion.

In this age of information overload, there was simply no way to expose students to the entirety of the field. In truth, even most top scholars could not keep up with all of the groundbreaking research and theorizing that was going on! The best I could do was to give students a "taste" of the rapidly expanding creativity literature-to give them the tools and the skills they would need to skillfully and systematically explore the topic of creativity on their own. My only option as an instructor was to loosen up a bit. So loosen up I did. But this change in my attitude and teaching approach did not happen overnight. It was a slow process, sometimes unconscious and often considerably painful. I found it excruciating to remove readings or sometimes even an entire topic from the syllabus. But such revisions were necessary if new topics were to be added and students were to have adequate time to engage in meaningful discussion. Importantly, the historical/foundational readings stayed.

One of the biggest benefits of FirstClass, and eventually Sakai, was the ease with which groups of students could "meet" outside of class time, share written work and ideas, engage in discussion, and chronicle their creative process. As mentioned earlier, over time, students became increasingly intrigued by entrepreneurship and design thinking. In an effort to capitalize on this interest, I decided to infuse some real-world product development experiences into the syllabus. Towards this end, by 2002 or so, I had incorporated into the course an Innovation Group component. At the start of the semester, class members selfsegregated into innovation groups of four or five according to areas of interest. Their charge was to spend the first part of the semester researching an area of need-something lacking for the betterment of a specific group or society as a whole. Next, they were to generate ideas for potential products (physical or virtual) that could help alleviate that need. Finally, they were to choose one of those product ideas and generate a prototype. In any given semester, only a few seminar students had had programming or engineering experience. As a result, the majority of the products they came up with were virtual in nature. Over the years, students devised a number of a phone apps. One such innovation was designed to facilitate cross-campus communication about current issues and events. Another app provided upto-the-minute information about the whereabouts of the Wellesley-MIT shuttle bus. Moving beyond the concerns and needs of the Wellesley College campus, one innovation group put together a website instructing users about the "Fast Fashion" movement and giving them step-by-step assistance in responsibly reducing their own wardrobes. Additionally, another group developed online tools designed to improve student accessibility to mental health resources, raise awareness of the resources available, and help ensure that students would feel comfortable utilizing those outlets.

Clearly, this innovation group component assumed that products produced would reflect positive creativity. Additionally, in fact, early on, before I came to make this an 
explicit requirement, seminar members naturally gravitated to the positive end of the continuum. In fact, over time, I found that this assignment had at least one beneficial but totally unintended consequence. In devising their projects, students were naturalistically introduced to the notion of positive vs. negative creativity; and their experiences in their innovation groups generated a good deal of valuable class discussion about this distinction. Students were especially eager to explore research and theorizing surrounding so-called "malevolent creativity," and they were energized by the question of whether it is ever appropriate to place a value judgment on any demonstration of creativity. The class discussed cases of a product or idea being deemed novel and useful (even if that usefulness was for nefarious ends) and wondered whether novelty and usefulness might not be sufficient creativity criteria. They wrestled with issues of morality and explored the relation between creativity and integrity [19]. Additionally, they debated about the classification of creative endeavors resulting in unintended and unanticipated negative consequences [20] and questioned whether it is the creator's obligation to envision these potential outcomes as part of the creative process.

As Sternberg and Chowkase [21] correctly point out:

Many investigators emphasize that judgments of creativity are influenced by one's sociocultural and historical contexts. That is, creativity has a meaning within a sociocultural context that defines particular innovations as both novel and creative. It would make sense, therefore, that positive creativity may also be defined in a sociocultural manner. What is deemed positive in one sociocultural context may be judged as negative or neutral in another sociocultural context (p. 237).

These issues of cultural context were not at all lost to me or my students. I cannot pinpoint exactly when it was that I started thinking seriously about cultural factors that might impact the interface between motivation and creativity; but over time, my own empirical research projects and theoretical model building came to incorporate a culture component $[22,23]$. Seminar students were enthusiastic about helping me to tease apart the complexity of factors that might impact the interface between motivation and creativity. They welcomed opportunities to broaden the discussion to include cultural factors potentially impacting their own creative performance and demonstrated surprising insight when examining the ubiquitous example of the French magazine Charlie Hebdo publishing (and then republishing) cartoons of the Prophet Mohammed, leading to the deadly terrorist attack in 2015.

The culmination of all of this seminar activity was two-fold. As a first step, seminar members did a careful reading of a book that might as well have been written by someone hell bent on DEBUNKING each and every understanding my students and I had spent the semester building. It was as if Robert Weisberg had gotten hold of the syllabus and made the commitment to demonstrate why every journal article assigned, every theory introduced was wrong. I initially assigned Weisberg's (1986) Creativity, Genius and Other Myths: What You, Mozart, Einstein and Picasso Have in Common [24] and then replaced that book with Weisberg's 1993 update Creativity: Beyond the Myth of Genius [25]. Students were angry, really angry, at this author, who dared to maintain that there is really nothing special about what we wrongly label as creative thinking, problem solving, or production. But, in my mind, seminar members' concerted efforts to argue against Weisberg's demystifying of creativity offered the perfect vehicle for summarizing and solidifying the semester material in their minds. In fact, when this book went out of print, I worked hard to secure every used copy that I could - ensuring that my future students would have the same opportunity to hone their own understanding.

Right from the start of the teaching of this course, also required at the close of the semester was a final written paper focused on a topic of each student's choosing. Ideally, students were to select an area of interest early in the semester so that their research process could begin and their ideas would have time to germinate. Towards this end, individual meetings with me the instructor as well as deadlines for paper outlines and first drafts were 
built into the syllabus. In retrospect, this assignment (or rather how students approached this assignment) may be the most striking of all the examples of seminar evolution over time. In the mid 1980s when this course was first offered, Internet search engines, and indeed the Internet itself, were not yet available. Research for a paper entailed multiple trips to the library, perhaps multiple libraries, and the Xeroxing of countless pages of book chapters and empirical journal articles. Over time, inter-library loan systems came to facilitate this process; and in more recent years, a variety of Internet search engines have made it possible for students to identify and then read even the most recently published journal articles without ever having to leave the comfort of their own dorm rooms. Was this evolving ease of access to materials accompanied by increasingly more sophisticated, far-reaching or complex student final papers? Overall, I would say not. The amount of effort and interest shown by students remained fairly consistent across the decades. While gaining access to readings may have become greatly simplified, it is possible that the evergrowing volume of available resources has served to challenge, confuse, and sometimes even paralyze students new to the study of creativity.

Additionally, consistent across the decades was student interest in enrolling in and reported satisfaction with the contents of the seminar. Right from the start in 1985, there was always a considerable waitlist of those hoping to add the class. Across the decades, this course maintained the reputation of being both fantastic AND highly demanding. Student course evaluations were also especially consistent and highly positive, although some of the specific aspects of the seminar that students most valued, the very tone and tenor of the course, did change over time. Students gradually came to focus less on the "me" and more on the "we". Over time, they were less interested in exploring either their own, personal creativity or the creativity of eminent individuals and far more excited to tackle issues of creativity from a global perspective. As online tools became more sophisticated and easier to use, seminar members' appreciation of computer-based discussions outside of class time also grew, and this enthusiasm also spilled over to include in-class conversations. In the last few years that this course was offered, in-class discussion was especially sophisticated and vibrant - to the point that I often did not have time to present during class much of the material I had prepared.

What might other creativity "experts" have had to say had they gained access to my seminar materials? Apart from the particulars of group work, individual student projects and writing assignments, my guess is that many of my colleagues might suggest that this course was a bit too much "all over the place". In part, I would agree with them but would be quick to point out that this seeming chaos was simply a reflection of the state of creativity scholarship as a whole. In 2010, Teresa Amabile and I published a review of the creativity literature in the Annual Review of Psychology [1]. As we put together that review, we were consistently struck by a growing fragmentation of the field. For the first few decades of psychological investigation of creativity, there were a relatively small number of "big questions" that most investigators focused on. But beginning around 1990, there has been "a virtual explosion of topics, perspectives, and methodologies in the creativity literature" (p. 571). It was our firm conclusion that investigators in one subfield often seem entirely unaware of advances in another. Why should not an undergraduate seminar reflect the very disjointedness of the study of creativity as a whole? Any attempt to neatly package the creativity literature would not have, in my opinion, been fair to students. In fact, I decided long ago that I would never adopt a creativity textbook for this very reason. My goal (stated or unstated) was always to immerse seminar members in this fascinating field-to expose them to the evolution of the theorizing, scholarship, and research that has shaped both our understanding of and confusion about the creative process. Only then could they experience, first hand, the juxtaposition of frustration and excitement that comes when one set of questions (never fully answered) leads to a whole new set of possible investigations-the sheer beauty of it all!

What does this collection of course materials gathered over 33 years reveal? Additionally, am I the best person to conduct this analysis? Without question, this retrospective 
examination of the evolution of a seminar is somewhat subjective. Data in the form of syllabi, student papers and projects, online discussions and course evaluations are irrefutable; but this analysis is, of course, tempered by my own lived experience. Yet who better than the creator and decades-long instructor of this course to chronicle its evolution? Written records and course artifacts fail to tell the complete story. Only aided by a review of my personal notes and recollections can the many intricacies of everything from decisions about course content and instructional approach to student interests and attitudes be revealed.

In my teaching of this creativity seminar, I was always committed to exposing students to a mix of what I found to be especially interesting and important and what experts in the field deemed essential. Decades of seminar development reflect my own evolution as a teacher, researcher, and theoretician as well as of the evolution of student sensibilities over time. Would I change the name of my seminar to "Positive Creativity" were I to teach it again? Probably not. Most every seminar member began the semester assuming that creative efforts would be directed at making the world a better place. Very few had ever considered that there might be a dark side to the creativity equation. In my mind, it was essential for students to explore BOTH the positive and the negative sides of creativity. While positivity certainly did reign supreme in this seminar, professor and students alike found the malevolent creativity literature to be especially interesting. There were thirtythree years of exciting, confusing and sometimes even joyful, exploration and debate.

Funding: This research received no external funding.

Institutional Review Board Statement: Not applicable.

Informed Consent Statement: Not applicable.

Data Availability Statement: Not applicable.

Conflicts of Interest: The author declares no conflict of interest.

\section{References}

1. Hennessey, B.A.; Amabile, T.M. Creativity. Annu. Rev. Psychol. 2010, 61, 569-598. [CrossRef] [PubMed]

2. Guilford, J.P. Creativity research: Past, present, and future. Am. Psychol. 1950, 5, 444-454. [CrossRef] [PubMed]

3. Jackson, P.; Messick, S. The person, the product and the response: Conceptual problems in the assessment of creativity. J. Personal. Soc. Psychol. 1965, 33, 309-329. [CrossRef] [PubMed]

4. Rothenberg, A.; Hausman, C.R. (Eds.) The Creativity Question; Duke University Press: Durham, NC, USA, 1967.

5. Runco, M.A.; Albert, R.S. Creativity research: A historical view. In The Cambridge Handbook of Creativity; Kaufman, J.C., Sternberg, R.J., Eds.; Cambridge University Press: Cambridge, UK, 2010; pp. 3-19.

6. Rhodes, M. An analysis of creativity. Phi Delta Kappan 1961, 42, 305-310.

7. Clouzot, H.-G. The Mystery of Picasso; Image Entertainment: Los Angeles, CA, USA, 2003.

8. Harris (Ed.) Pollock; Sony Pictures Home Entertainment: Culver City, CA, USA, 2000.

9. Stone, I. Lust for Life; Penguin Books: London, UK, 1984.

10. Baron, F.; Montuori, A.; Barron, A. (Eds.) Creators on Creating: Awakening and Cultivating the Imaginative Mind; Penguin: London, UK, 1997.

11. Potok, C. My Name Is Asher Lev; Anchor Books: New York, NY, USA, 1983.

12. Conway, F. Body and Soul; Random House: New York, NY, USA, 1993.

13. Hennessey, B.A.; Amabile, T.M. Consensual assessment. In Encyclopedia of Creativity; Runco, M., Pritzker, S., Eds.; Academic Press: Cambridge, MA, USA, 1999; pp. 347-359.

14. Amabile, T.M.; Hennessey, B.A.; Grossman, B. Social influences on creativity: The effects of contracted-for reward. J. Personal. Soc. Psychol. 1986, 50, 14-23. [CrossRef]

15. Eisenberger, R.; Cameron, J. Detrimental effects of reward Reality or myth? Am. Psychol. 1996, 51, 1153-1166. [CrossRef] [PubMed]

16. Hennessey, B.A.; Amabile, T.M. Reward, intrinsic motivation, and creativity. Am. Psychol. 1998, 53, 674-675. [CrossRef]

17. Edwards, B. Drawing on the Right Side of the Brain; Bay State Book Company: Sharon, MA, USA, 1989.

18. Leff, H. Playful Perception; Waterfront Books: Georgetown, SC, USA, 1984.

19. Beaussart, M.L.; Andrews, C.J.; Kaufman, J.C. Creative liars: The relationship between creativity and integrity. Think. Ski. Creat. 2013, 9, 129-134. [CrossRef]

20. Reiter-Palmon, R. Are the outcomes of creativity always positive? Creat. Res. Appl. Theory 2018, 5, 177-181. [CrossRef]

21. Sternberg, R.J.; Chowkase, A. When we teach for positive creativity, what exactly do we teach for? Educ. Sci. 2021, 11, 237. [CrossRef] 
22. Hennessey, B.A. The creativity-motivation-culture connection. In The Palgrave Handbook of Creativity and Culture Research; Glăveanu, V.P., Ed.; Palgrave Macmillan: London, UK, 2016; pp. 125-158.

23. Hennessey, B.A. Taking a systems view of creativity: On the right path toward understanding. J. Creat. Behav. 2017, 51, 341-344. [CrossRef]

24. Weisberg, R.W. Creativity, Genius and Other Myths: What You, Mozart, Einstein and Picasso Have in Common; W.H. Freeman \& Co.: New York, NY, USA, 1986.

25. Weisberg, R.W. Creativity: Beyond the Myth of Genius; W.H. Freeman \& Co.: New York, NY, USA, 1993. 